\title{
Exploring eudaimonia through meaningful work narratives within work integration social enterprises
}

\author{
Tamara Bilbija \\ Department of Business Administration and Marketing, University Jaume I, \\ Castellón de la Plana, Spain, and \\ Jack Stout Rendall \\ Yunus Centre for Social Business and Health, Glasgow Caledonian University, \\ Glasgow, UK
}

\begin{abstract}
Purpose - The purpose of this paper is to provide new evidence on the different dimensions of well-being that can occur in work integration social enterprises (WISEs). This study aims to call for a future discussion on the role of meaningful work (MW) and its impact upon well-being beyond satisfaction.

Design/methodology/approach - Explorative interviews were undertaken with professional workers and beneficiaries within a Spanish WISE. These interviews aimed to uncover similarities and differences across aspects of what makes work meaningful to them as workers. Both eudaimonic and hedonic dimensions of well-being were used to analyse the data.

Findings - Different groups of employees show that professional employees (those working in the WISE, not because of their disadvantages in the labour market) create their narratives based on MW experiences (eudaimonic well-being), whereas beneficiaries (those working in the WISE because of their disadvantages in the labour market) often describe how satisfied they are at work (hedonic).

Originality/value - The concept of MW within WISEs to achieve well-being for both beneficiaries and professional workers could be enhanced through discussion of the different types of well-being that are being realised in such settings. Engaging with the concept of "eudaimonia" helps the authors to achieve this aim.
\end{abstract}

Keywords Well-being, Job quality, Meaningful work, Hedonic, Work integration social enterprise, Eudaimonia

Paper type Research paper

\section{Introduction}

There is a growing literature around the impact of work integration social enterprises (WISEs) on the health and well-being of professional employees (i.e. those not disadvantaged in the labour market and working in the WISE) and beneficiaries (those working in the WISE because of their disadvantages in the labour market). This

Tamara Bilbija and Jack Stout Rendall. Published by Emerald Publishing Limited. This article is published under the Creative Commons Attribution (CC BY 4.0) licence. Anyone may reproduce, distribute, translate and create derivative works of this article (for both commercial and noncommercial purposes), subject to full attribution to the original publication and authors. The full terms of this licence maybe seen at http://creativecommons.org/licences/by/4.0/legalcode

Received 24 February 2021

Revised 28February 2021

3 March 2021

3 March 2021

Accepted 3 March 2021

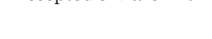


SEJ

17,4

differentiation of workers and beneficiaries follows the approach of Amin (2009), where staff are considered to often be in positions of managers or senior and experienced workers, whereas employees are those working in the WISE as a result of disadvantage in the labour market. Most of the literature on the impact of WISEs seeks to uncover the extent to which particular groups, such as beneficiaries are satisfied in their workplace (Villotti et al., 2012), while other focus on other elements of well-being such as self-esteem and how this can impact upon factors such as job tenure (Lanctôt et al., 2012) or on levels of stigma from the local community (Krupa et al., 2019). Still, a smaller number of studies have brought into focus the role that meaningful work (MW) plays in the impact of WISEs. These studies have begun to unpack what it means for work to be meaningful to service users (Macaulay et al., 2018). Interaction with others (Ho and Chan, 2010), availability of training opportunities (Teasdale, 2010) and favourable working conditions all seem to be key to realising wellbeing in such settings.

However, we consider that there are two aspects of this literature that require further unpacking and exploration. Firstly, there is a lack of focus on the impact that WISEs may have on those (individuals) that work in social enterprises. That is, people distinct from those explicitly recognised as receiving the services that a WISE may have been set up to deliver. Secondly, we argue that further detail on the concept of MW to achieve well-being within WISEs could be enhanced through discussion of the different types of well-being that are being realised. Doing so would lend much needed nuance to discussions about workers' well-being within WISEs. Engaging with the concept of "eudaimonia" - a Greek word roughly translated as "human flourishing" - as we will discuss - helps us to reach this goal.

Our study is organised as follows. We explore long-standing understandings about the eudaimonic dimension of well-being, recognising its origins and its relative underdevelopment in relation to discussions of social enterprise and well-being in the extant literature to date. After explaining the methods used in our study, we proceed to draw upon our empirical findings from research on MW in WISEs. Exploratory interviews were undertaken with a range of workers within a pioneering Catalan WISE called "La Fageda". They have been operating successfully for more than 30 years while offering remunerated work to beneficiaries. The aim of these interviews and subsequent analysis were to develop an understanding of the similarities and differences across aspects of what makes work meaningful to professional employees and beneficiaries. Our study uncovers that there is a complex mix of both eudaimonic and hedonic dimensions of well-being realised within WISEs. Some professional employees build narratives to describe their experience at work that is built on meaningfulness and how that plays a key role in realising well-being (as part of the eudaimonic dimension), while others, particularly beneficiaries, build their well-being narratives based on how satisfied they felt at work (hedonic dimension). Our chapter concludes by outlining how and why the concept of eudaimonia is important to social enterprise research and explains that further research is needed to help extend understanding of how WISEs impact on their various stakeholder groups from a well-being perspective.

\section{Well-being and eudaimonia}

Since ancient Greek times, philosophers such Socrates, Plato and Aristotle have been concerned with what it means to live a "good life". These concerns are analogous to what, today, we refer to as "well-being". Different interpretations of what a "well-lived life" means continue to encourage debate amongst researchers. In his Nicomachean Ethics, Aristotle proposed eudaimonia as the goal of fulfilling life with a "certain activity of the soul in accord with complete virtue" (Aristotle, p. 23). From Aristotle's point of view, a well-lived life is one 
spent on worthwhile aims. Still, the issue of well-being is a complex question that requires deep reflection (Tiberius, 2014), as the issue of what "worthwhile" means in this context is highly subjective.

Most empirical work assessing well-being, particularly in contemporary psychology, is based on the notion of subjective well-being (Diener, 2012) where assessment involves investigating the presence of positive feelings, the absence of negative feelings and overall satisfaction with one's circumstances. Some psychology scholars go beyond the subjective well-being framework in search of a more expansive perspective on well-being (Ryff, 1989; Ryan and Deci 2001) explaining that the eudaimonic perspective is related to the idea of fulfilling purpose and finding meaning reflected as "optimal functioning" in life, emphasizing intersubjective experiences through positive relationships with others.

A strict interpretation of eudaimonia though, conforming with Aristotle's teachings, would relate to what is worth pursuing in life, what makes life meaningful and not necessarily the subjective experience of contentment (Heintzelman, 2018). Staying true to Aristotle involves examining how eudaimonia involves "behaving virtuously" towards others (Annas, 1995) and

[... .] should not be understood as referring to any kind of subjective experience or 'richer feeling of happiness' but is rather about a good and valued way of living that can produce happiness, vitality and wellness as its by-products. Furthermore, eudaimonia is especially found in those manners of living and pursuits that reflect our positive human nature. (Ryan and Martela, 2016, p. 109)

We think that the eudaimonic perspective provides a framing that can help build a deeper understanding of well-being, and is pertinent to the conditions of WISEs because of the opportunities that these organisations provide for workers to find meaning in their lives, as well as to contribute to the meaning in the lives of colleagues and/or customers. Occupations that have a direct impact on others have been found to be more meaningful for those who work and contribute in such settings (Bryce, 2018). Indeed, by working to contribute towards the well-being of others can help in creating purpose in one's own life.

Extant research findings show that there is potential for social enterprises to positively affect the health and well-being of individuals and communities (Roy, Donaldson, Baker, et al., 2013; Elmes, 2019; Blake, 2019). From the sparse range of studies that attempt to highlight the impact of WISEs (Gidron, 2014; Jeffery, 2005), there remains a lack of evidence regarding how the well-being of workers within these organisations is affected (Williams, Fossey and Harvey, 2012). A growing body of literature (Chan, 2015; Ho and Chan, 2010; Munoz et al., 2015; Farmer et al., 2016) has started to provide evidence that WISEs can have positive impacts on workers' health and well-being. However, there are other types of workers in WISES - professional employees and managers - and there remains a lack of empirical evidence on how employment within WISEs can affect their well-being, as well as the intended beneficiary workers.

There is also research evidence about the positive well-being effects of WISE for beneficiaries, including non-vocational outcomes of mental health such as self-esteem (Ferguson and Islam, 2008), self-confidence (Ho and Chan, 2010), self-efficacy (Hazenberg et al., 2014), self-worth and empowering disadvantaged groups (Teasdale, 2010). However, there is a lack of evidence concerning how involvement with meaningful activities impacts well-being beyond only pleasant and positive feelings that bring personal benefit. Hedonic well-being relates to concern about the fulfilment of one's own needs and desires, often accompanied by feelings of pleasure. Eudaimonic well-being, in contrast, is related to meaningful actions (Steger et al., 2012; Bauer et al., 2008; Gallagher et al., 2009) but is often overlooked within the context of work (Bartels et al., 2019). Considering eudaimonia can 
offer a novel perspective on WISEs and well-being, especially regarding how and in what ways, workers describe their work as meaningful. There are currently published frameworks through which one can measure MW. Steger et al. (2012, p. 326) review these measurements and highlight that they have "developed erratically and on an ad hoc basis, while still demonstrating allegiance to a rather vague definition of MW". Steger et al. (2012) then developed a framework for measuring MW based upon the idea that MW is a subjective experience, that one can develop a meaning in life through work, and that people desire to contribute to the common good through their work. While Yeoman (2014) is keen to highlight that MW should be a right to which everyone is entitled to. This is even though the current conception of MW has been diminished:

$[\ldots]$ to the status of individual taste or preference, which it is no business of the state to promote. But this settlement is normatively inadequate when the centrality of work in modern societies makes it increasingly difficult for individuals to remedy non-meaningful work in other action contexts. (Yeoman, 2014, p. 236).

There is an important distinction between the meaning of work and MW (Rosso et al., 2010; Steger et al., 2012). The meaning of work is the meaning that could be attached to a job whereas the MW refers to how significant that job was in the development of meaning in their lives (Rosso et al., 2010). For example, work could just mean a wage, but it could also mean experiences of oppression or inequality. According to Steger, Dik and Duffy (2012), MW is positive in valence because of eudaimonic focus (purpose-oriented) rather than hedonic (pleasure-oriented).

Work has an instrumental value, providing means for living but it also offers opportunities to connect and to make contributions to others' lives, while building a sense of community between people. MW refers both to the context of work and to the job itself being understood as purposeful (Pratt and Ashforth, 2003). This conception often comes from organisational purpose, values and from intrinsic characteristics of work. As WISEs focus on improving the quality of life of disadvantaged workers, employees working in this context are ideally suited for exploring the idea of eudaimonic well-being at work. Exploring meaningfulness in WISEs through the roles and identities that workers have in organisations allows us to understand how these aspects might impact upon perceptions of MW. The methodology and methods used to reach this aim will now be detailed.

\section{Methodology}

In this study, the aim was to discover how different groups of employees (beneficiaries and professional employees) understand their well-being in WISEs, posing the following research questions: how is MW perceived in this organisational setting? And how does this impact the employees' well-being? Exploratory in-depth interviews were undertaken with professional workers and beneficiaries during a two-week stay in the organisation "La Fageda". The first author spent ( $8 \mathrm{~h}$ daily) at La Fageda and met participants for informal interviews, researching organisations documents, files and appearances in local and national media. Data presented was obtained during the first author's doctoral research. Ethical approval was obtained from Jaume I University Ethics Board. All interviewees were informed about the research aims and were provided with a consent form, which acknowledged that the data will only be used for research purposes.

\section{La fageda}

La Fageda is a pioneer WISE known for its yoghurt production and for employing workers with mental health issues in the Spanish region of Catalonia. More than half of employees 
experience mental illness. The organisation has been in operation since 1982 and is acknowledged for its social mission. Nowadays, La Fageda produces more than 40 million yoghurts per year. Its founder thinks that the value of La Fageda is "offering MW placing emphasis on a person's capabilities for all workers” (from interview). La Fageda has 307 employees, of which 160 are experiencing mental health conditions or cognitive disabilities. One of the most important impacts is that most of the workers experiencing mental illness hold paid employment. Recently this social enterprise started working with young people at the risk of social exclusion by incorporating beneficiaries' workers in different departments with the aim to re-integrate them back into work. Workers perform tasks in different departments such as fabric, dairy farming, gardening, warehousing and laboratory work. In total, 147 professional employees hold different positions within the organisation, coming from different backgrounds such as psychology or social work, quality control, marketing and sales or administration.

\section{Sampling}

Purposeful sampling was used as part of this rich case study approach (Patton, 2001). Interviews were held with 10 full-time paid workers, namely, 6 "professional employees" (4 female and 2 male) and 4 beneficiaries ( 2 female and 2 male). Professional employees worked in the fabric department (one), gardening project (one), human development department (one) and social department (one), all with full-time permanent contracts. Beneficiaries were aged between 20 and 40 and represented different disadvantages on the labour market; mental health issue (1), physically disabled (1) and young people at the risk of exclusion (2). One participant had permanent full-time employment, while the other three were on paid training. Beneficiaries were from the fabric department, laboratory and administration department. Rather than their real names, in this study, we use the names of the different departments that employees worked within (Table 1).

\section{Interviews}

Employees were asked to talk about their experiences in the WISE, discussing their personal situation and their interaction with others. Focus was placed on questions regarding employees own well-being, allowing an exploration of personal narratives related to the experience of working in the WISE (McAdams, 2008). The study used 10 audio recorded semi-structured interviews to collect data. All interviews were recorded, with consent and transcribed manually. Interview data helped to understand the extent to which employees experienced their work as meaningful, and the different experiences that contributed (or not)

\begin{tabular}{|c|c|c|c|c|c|}
\hline Employees & Department & Gender & $\begin{array}{l}\text { Time spent in } \\
\text { organisation }\end{array}$ & $\begin{array}{l}\text { Condition } / * \text { Contract } \\
\text { duration }\end{array}$ & \\
\hline Professionals & $\begin{array}{l}\text { Human development, } \\
\text { social department, } \\
\text { gardening project, fabric }\end{array}$ & Men and women & $\begin{array}{l}\text { From } 1 \text { year to } \\
20 \text { years }\end{array}$ & *Permanent employment & \\
\hline \multirow[t]{2}{*}{ Beneficiary } & $\begin{array}{l}\text { Fabric, administration, } \\
\text { laboratory }\end{array}$ & Men and women & $\begin{array}{l}\text { From six month } \\
\text { to more than } \\
10 \text { vears }\end{array}$ & - Mental health issues & \\
\hline & & & & $\begin{array}{l}\text { - Social exclusion } \\
\text { - Physical disability } \\
\text { *Permanent and } \\
\text { temporary employment }\end{array}$ & $\begin{array}{r}\text { Table } 1 . \\
\text { Characteristics of } \\
\text { participants selected } \\
\text { for the study }\end{array}$ \\
\hline
\end{tabular}


to their well-being. To achieve triangulation across different forms of data, we also used data from informal interviews and discussions carried out during the visits. Personal notes, organisation documents provided by the organisation and published documents by media were also used in the triangulation process.

\section{Data analysis}

Interview data were analysed thematically. Initial codes were generated inductively from the start of the data gathering process for both employees groups. Initial themes included: "well-being at work", "purpose", "meaningful activities", "learning", "opportunity", "needs" and "environment". These codes were then converted into larger superordinate themes that were related to the well-being of two different groups of workers. Themes were emerging from data but also from previous research on eudaimonic and hedonic well-being. Data was interpreted with the help of qualitative analysis software Atlas.ti. Data was collected in the Spanish language. It was originally transcribed and analysed in Spanish. Following this, the verbatim quotes used in the Findings section were translated into English. The first author is fluent with both English and Spanish languages.

\section{Findings}

The findings are presented in three sections below. The first theme relates to contribution to beneficiary's well-being and was taken as an important theme for professional workers for understanding their work as providing their lives with meaning. The professional employees recognised that MW was embedded in the purpose of the organisation: helping beneficiaries in day-to-day activities. This embedded purpose then contributed to their sense of (eudaimonic) well-being. Furthermore, professional employees were found to value the opportunity for "self-actualisation" offered within the WISE. The second theme relates to what was important for the beneficiary's well-being. They highlighted on-the-job learning and improving working skills as important. Beneficiaries valued the support they have at work and the opportunity for learning so that they could potentially achieve a better paid job in the wider labour market. Beneficiaries also expressed discontent with their current pay, which suggests that their motivation is, to an extent, extrinsic. Each theme is presented and explored, in turn, before being developed further in the discussion section.

\section{Theme 1 - Finding meaning in work for the common good: professional employees well-being}

Professional employees perceived their organisation's purpose in contributing towards good for others, as also meaningful and important for their own well-being. They tended to describe it as subjective experience but eudaimonic-oriented, rooted in activity where the work contributes to others' well-being.

[.. . ] Most people who are part of our project are in it because they have found a meaning in the work they do for others and for the common good. To be in the place where you can develop professional activity and be able to give something back to society. Until you don't try that you don't know how you can be enhanced as a person. (Professional Employee - Human Development Department)

The purpose of the organisation can create impacts beyond the work context, such as life experience. Professional employees did not create narratives about satisfaction with work regarding meeting their own needs but rather they related meaning as experiences that fulfilled their life in the context of work. This is a qualitatively different position than hedonic well-being, where one wants to maximise their own satisfaction and pleasure. 
Professional employees talked about their work relating it to caring about the well-being of users and how this is related to their development of MW:

Seeing others as a person, understanding their needs and challenges that they face. I wouldn't say it changed my whole life, but it did change the way I look at life. . . and I didn't experience that in other work contexts. (Professional Employee -Social Department)

Meaningfulness is created through the work one does with a greater cause, such as making a difference to important social problems. In an Aristotelian sense, "eudaimonistic" assumes that one is not pursuing for his own happiness, but for others, for their sake. This implication of prosocial motivation towards others may come from beliefs about the organisation in which work is rooted.

You have a project that you love, and you wanted it to work out because it's the topic you get emotional with. I guess it is a question of emotions. If it were a fabric with machines, I wouldn't be so excited nor motivated. But you are working with people, people that you take care of, and you want this project to work above all. (Professional Employee - Gardening Project)

Being connected to beneficiaries and having the opportunity to work day-to-day with them and see their development helped professional employees to perceive their work as meaningful. One of the professional employees from the social department noticed how motivation came from realizing that life improved for the beneficiary:

I am still in love with the project as in the beginning. Because every day I see very clearly the goal that we have. I see people who are having difficulty coming to work every day and having difficulty in doing activities. I also see how, after a while, a person is growing and is gaining confidence. Many changed their lives here. This is my motivation. (Professional Employee Social Department)

Professional employees perceived that their work in the WISE was different from previous work experience in the for-profit sector and this was reflected in the opportunity to exercise virtues, such as contributing towards beneficiaries (others) well-being. As a result, relationships are more "caring" and tolerant, as value is perceived if beneficiaries are satisfied or their life is improved during the work rather than what might be the case in a mainstream workplace. This allowed professional workers to understand that their work has a direct impact on the lives of beneficiaries.

We found that professional employees were inspired through purposeful work, which echoes with the human desire of engaging within work that can help others. For them, this was a source of inspiration and commitment but also of the joy of "being in the right place", which is eudaimonic in that sense.

I'm very connected with my work. I feel that I'm in the right place, feel very fortunate, so ask myself will I be on the level to accomplish the challenge in front of us. I wonder how I can improve my capacities. But every day I enjoy it, I love to work and especially love my work here. (Professional Employee-Social Department)

In other jobs I had the feeling that it was difficult for me to fit in, but here I felt immediately. I felt that I could develop my skills and realize my potential. (Professional Employee Occupational Therapy Service)

These quotes show the development of one's own potential is related to eudaimonic wellbeing in contemporary psychology. Professional employees explain that they have the opportunity to practice virtues at work. During the interviews when asked about the 
perception of the work they do in WISE; professional employees highlighted the relationship between work and their life philosophy:

My work is part of my philosophy of life. I work the same as I live. I feel full. I give, and at the same time, I receive a lot. It's rewarding. I think life is like a circle. I try to feed the project and at the same time the project feeds me. It allows me to fulfil my need to help others and at the same time in a natural environment. (Professional Employee - Residence Service)

Especially for those professional employees that have direct contact day-to-day with beneficiaries, they described well-being at work reflected contributing to solve problems and facilitate "happiness" of beneficiaries:

I set myself a goal and I achieve it. For example, I propose to resolve a conflict. When I see it done, it is a great personal satisfaction. Seeing their (beneficiaries) happiness changes my day. These are the hours that I create a lot of bonds with them. I don't have to be as busy at work and everything is smooth. (Professional Employee - Fabric Department)

Yet, for professional employees, it was acceptable to have lower wages in return to work on something that brings intrinsic motivation to them. Being intrinsically motivated and not by extrinsic factors may well be a sign of their eudaimonic preferences.

Do not think we are here for money. My director, myself, we are here earning far less than we used to. I think that the salary is fairly secondary. As we use to say here, we do not feed bellies we feed souls. I have been offered (work in other enterprises) and I have said no; I am happy here.

(Professional Employee - Fabric Department)

Other professional employees also emphasise the idea that as professionals they may be better paid elsewhere in the for-profit sector, and some of them come from multi-nationals, but they were attracted to this WISE because of the opportunity to do something meaningful.

The people who are part of the enterprise, want to be here for many more reasons than just the salary and, in our case, this highlights the great commitment that we have with the Project. (Professional Employee-Human Development Department).

\section{Theme 2 - Satisfaction at work: well-being of beneficiaries}

Working in an organisation with a suitable environment that can provide the opportunity for MW may be related to fulfilling psychological needs and contributing towards mental health. What is important for professional employees was becoming enriched as a person, despite difficulties (rejected hedonism) through self-development. For beneficiaries, work in the organisation was understood as an opportunity to enhance their personal development. Regarding what is important to them, beneficiaries stress the relationships with others; mainly through the support they receive, resulting in improvements in self-esteem and selfefficacy. This was particularly important for employees experiencing mental illnesses:

I had very low self-esteem before I came here. My relationship with my partner and my family has improved. Íve noticed a change, noticed a lot that my self-esteem went up and had more motivation to work, more responsibility. I had a responsibility that sometimes others don't give you (Beneficiary Worker - Laboratory Department)

Beneficiaries did not talk about helping others to describe how they understand their work or how this affected their job. During the interview, they expressed narratives about wellbeing being based on what they lack or receive from current employment. Highlighting opportunities for learning and both personal and professional development affected wellbeing in a positive way, this was expressed through satisfaction with work: 
I have learned things, before I was not punctual, but I improved. Before, I was late since I had a half hour break and it passed quickly. Now I am punctual. In another factory it has nothing to do with here, there you haven't got neither breaks nor anything, there is no same comfort as here. Here we can go out to drink coffee, smoke the cigar. (Beneficiary Worker-Fabric 2)

The opportunity to learn and improve existing skills was considered important to beneficiaries. According to this, employee opportunity for learning is linked to the motivation for improving his life:

\section{Work integration social enterprises}

I really like learning. Here you can learn. They told me they will send me to be a mechanic. First

Íll go to study mechanics and then come back here again. (Beneficiary Worker-Fabric 1)

One employee, while explaining what is important to him, explains how happy he is when his needs are satisfied:

My goal is to come happy to work, come with motivation and to get well with workers and to be happy and have good vibes. Right now, I am very well, because they have changed my shift and I come to work in mornings (Beneficiary Worker-Fabric 2)

Beneficiaries were concerned about the satisfaction of their needs, this then reflected through to healthier relationships with others, greater flexibility, increased comprehension of tasks, learning and being motivated. As they did not have the opportunity to contribute to someone else's well-being rather than their own, they gave priority to use the support available to them.

They reported low satisfaction when considering how much they had been paid for their work. Beneficiaries perceived that they were paid less than would be the case in the forprofit sector or other organisations in the wider labour market.

I would not go only because somewhere else would pay me more, but if they are good and pay more than I would leave. I am paid truly little. For eight hours I consider it is poorly paid (Beneficiary Worker-Administration Department)

I would stay but the problem is salary, it is minimal. A minimum wage so I try, but it is hard. I worked somewhere else and earned more, that is why here sometimes I think that I'm wasting my time. For earning little and working hard. (Beneficiary Worker-Fabric 1)

While discussing the "money issue" some beneficiaries mentioned that they worked before in a similar sector and earned more, which contributes to the theme of extrinsic motivation.

\section{Discussion}

The presented findings highlight that social enterprises, through the lens of MW, can offer well-being benefits that, in some cases, goes beyond more "simplistic" pleasure- and satisfaction-seeking narratives. This would suggest that when considering well-being generated within social enterprises, there is a need to consider what kind of well-being we are talking about: eudaimonic well-being would seem to deserve more of our attention. Moreover, the findings that have been uncovered across two different employee groupings are currently under-represented in the literature, which we have called "beneficiaries" and "professional employees".

Building on the concept of "MW", the tendency for professional employees to implicate the role of helping others and see their work as "extraordinarily ordinary" (Amin, 2009) - we argue that it is likely to occur in WISEs where employees have direct contact with beneficiaries and exercise professional activities that impact positively upon the lives of others. The results presented suggest that professional employees in WISEs emphasise the 
importance of MW and in contributing to others when talking about their psychological well-being (eudaimonic). On the other hand, beneficiaries are often in a vulnerable position within the labour market, the opportunity to enhance their skills can decrease their vulnerability (Kyndt et al., 2013), so they use narratives of satisfaction with their job and organisation, which is seen as an opportunity for learning, gaining useful experience or improving self-esteem. This might be the case because of the different roles that employees have in WISEs. Professional employees often perceive themself as agents that contribute to others well-being, which compensates them for understanding their work as meaningful and as a source of personal fulfilment. Meanwhile, beneficiaries perceive their jobs as less "extraordinary" because of their role of being served or not having the same opportunity to contribute to the well-being of others. Therefore, for them, working in WISE is an opportunity to satisfy their own needs.

Perceptions of meaningfulness and personal fulfilment may be highlighted by the consideration of pay within the WISE. Some workers find intrinsic worth in their work, which, to an extent, negates the desire for fulfilment of remunerative satisfaction. While other workers, who are more concerned with their own personal fulfilment, may seek a higher wage than what the WISE can provide, and therefore, they may seek work in the wider labour market. Yet, these financial considerations need to be coupled with a wider understanding of the impact that financial remuneration can make for individuals and the extra forms of assistance that can be provided within WISEs when compared to organisations in the wider labour market. This is consistent with literature that suggests that for low-skilled employees, sometimes employment in the social economy might be considered as a "temporary stopping point" (Amin, 2009).

Beneficiaries may also understand themselves as those who are there to be served rather than those who serve the mission. Thus, the different identities in an organisation are likely to influence how they perceive MW (in terms of helping others and advancing others wellbeing). One explanation for this phenomenon could be related to the identity that employees create in WISE. Social identity theory (Tajfel, 1979) offers a useful lens for explaining how belonging to a certain group (for example, being a member of a team in a workplace) creates a sense of identity and provides a source of values or goals. Some groups, as might be the case for professional employees, share belief that contributing to others is something good and the right thing to do, which leads them to create MW narratives. People are part of groups at work. Through roles that provide them with responsibility, they can build and confirm their identity (Tajfel, 1979). Employees are pro-socially motivated when they are directly connected to those they contribute to, for example, beneficiaries who are directly affected by their work (Blau and Scott, 1987). If workers have contact with beneficiaries, it is related to their commitment and prosocial motivation (Grant, 2007).

Regarding eudaimonic and hedonic well-being, we do not suggest that eudaimonia is necessarily "superior" to hedonic well-being. Ward and King (2016) also add that eudaimonia includes, to an extent, being satisfied with oneself and we can see how that would translate then into important aspects such as self-efficacy, self-esteem and selfawareness. Indeed, a certain amount of subjective well-being may well be needed for motivation, personal growth and eudaimonic development (Law and Staudinger, 2016) and while our findings show that professional employees are generally satisfied, this may well be down to the existence of a mix of both eudaimonic and hedonic dimensions, albeit there is important evidence that eudaimonia is related to contributing in life of others (Huta et al., 2012). In the context of WISEs, meaningfulness can be embedded into the organisational purpose and mission of the organisation. Organisations such as WISEs can influence how employees perceive their work as meaningful. Similarly, this approach is adopted by Blake 
(2019) adopting a MacIntyrean perspective on social enterprises, where commitment to social purpose offers participation in virtuous practices while seeking excellence and improving the well-being of those involved as a result of those actions.

Blake (2019) explains that social enterprise beneficiaries, through the seeking of "internal goods" within work practices, contributed to their own well-being and meaningful perception of their contribution. In regard to MW, Pratt and Ashforth (2003, p. 311) propose that work (or the context of work) is understood as purposeful and significant when answering the question "why am I here?", while loss of meaning of work is frequently related with indifference and detachment from the work itself (May et al., 2004). Commitment to MW, contribution to others and society, living and working in line with virtues are all characteristics of eudaimonic work that are often overlooked in well-being research. Brolis and Angel (2015) suggest future studies are needed to understand the motivation of social enterprise workers and the potential impact on their well-being beyond job satisfaction. Also, consistent with Bell and Haugh (2014), we still know little about the motivation of employees in social enterprises. However, examining the differences in identity within two employee groups, as was case in this WISE, suggests there might be differences in understanding MW and its impact on well-being in different contexts (for example, those facing different disadvantages in the labour market).

\section{Conclusion}

This chapter contributes to the discussion of eudaimonic well-being in social enterprise, particularly WISEs. While philosophical questions on eudaimonia have emerged in psychological research, we advance perspectives on eudaimonia through recognizing that the human good consists of both individual and collective goods, and these are commonly seen in the impacts of WISEs. While a subjective approach common within psychology was used here, we note from this approach that eudaimonic well-being comes from the community context in which WISEs are situated, help to create and stimulate. This might add to future psychological research on eudaimonia where there is a tendency to focus on the individual, rather than the community context.

Organisations such as WISEs aim to contribute to well-being by enabling opportunities for MW. Such organisations committed to supporting marginalised groups enable employees to see their social aim as more important than extrinsic rewards, such as bonuses or other forms of monetary reward. Moreover, the narratives of WISE workers have provided themes on how MW is imbued with virtue. As we are social beings, caring for others, building relationships, striving for common well-being while achieving our highest potential, are all related to meaningfulness, which can be achieved by working in such organisations. MW as a topic unites various disciplines and can prove useful for crossdisciplinary research (Pratt et al., 2013). A more comprehensive approach to well-being is required, consistent with the idea of eudaimonia, but going beyond subjective well-being (positive affect, low negative affect and satisfaction). Especially, as there is a gap when referring to the well-being of those employees within social enterprise who are not only users but professional workers.

We have added to the discussion about the well-being of those social enterprise workers through an unpacking of philosophical and psychological approaches in social enterprises. We have contributed to the psychological discussion of eudaimonic well-being and its relationship with MW. Promoting eudaimonia in a work context may be important in helping to prevent mental illness and promoting positive mental health and well-being at work. Using the lens of eudaimonia can help contribute to this discussion through an increased awareness of how practice, contributions and virtues help to create an MW 
environment especially in social enterprises. This study should lead to further empirical work to determine whether MW and eudaimonic well-being influence professional workers in WISEs on a larger scale, particularly across industries and cultures. The interdisciplinary nature of this topic and applicability in social enterprise, as well as in organisational psychology research, make this a promising topic for further research in the future.

References

Amin, A. (2009), "Extraordinarily ordinary: working in the social economy", Social Enterprise Journal, Vol. 5 No. 1, pp. 30-49.

Annas, J. (1995), "Happiness and the demands of virtue", The Morality of Happiness, Oxford University Press, New York, NY, pp. 426-436, doi: 10.1093/0195096525.003.0022.

Bartels, A.L., Peterson, S.J. and Reina, C.S. (2019), "Understanding well-being at work: development and validation of the eudaimonic workplace well-being scale”, Plos One, Vol. 14 No. 4, doi: 10.1371/ journal.pone.0215957.

Bauer, J.J., McAdams, D.P. and Pals, J.L. (2008), “Narrative identity and eudaimonic well-being”, Journal of Happiness Studies, Vol. 9 No. 1, pp. 81-104.

Bell, B. and Haugh, H. (2014), "Working for a social enterprise: an exploration of employee rewards and remuneration", in Denny, S. and Seddon, F. (Eds), Social Enterprise: Accountability and Evaluation around the World, Routledge, London, pp. 67-84.

Blake, J. (2019), "Utilising a MacIntyrean approach to understand how social enterprise may contribute to wellbeing", Social Enterprise Journal, Vol. 15 No. 4, pp. 421-437.

Blau, P.M. and Scott, W.R. (1987), “The concept of formal organization”, in Shafritz, J.M. and Ott, J.S. (Eds), Classics of Organization Theory, Dorsey, Chicago IL, pp. 187-192

Brolis, O. and Angel, V. (2015), "Workers' motivations and managerial practices in not-for-profit social enterprises", 5th EMES Conferences Selected Papers series (ECSP), Helsinki.

Bryce, A. (2018), "Finding meaning through work: eudaimonic well-being and job type in the US and UK”, SERPS no. 2018004, Sheffield Economic Research Paper Series.

Chan, A.N.W. (2015), “Social support for improved work integration”, Social Enterprise Journal, Vol. 11 No. 1, pp. 47-68.

Diener, E. (2012), "New findings and future directions for subjective well-being research", American Psychologist, Vol. 67 No. 8, pp. 590-597, doi: 10.1037/a0029541.

Elmes, A.I. (2019), "Health impacts of a WISE: a longitudinal study", Social Enterprise Journal, Vol. 15 No. 4, pp. 457-474.

Farmer, J., De Cotta, T., McKinnon, K., Barraket, J., Munoz, S.A., Douglas, H. and Roy, M.J. (2016), "Social enterprise and wellbeing in community life", Social Enterprise Journal, Vol. 12 No. 2, pp. 235-254.

Ferguson, K.M. and Islam, N. (2008), "Conceptualizing outcomes with street-living young adults grounded theory approach to evaluating the social enterprise intervention", Qualitative Social Work, Vol. 7 No. 2, pp. 217-237.

Gallagher, M.W., Lopez, S.J. and Preacher, K.J. (2009), “The hierarchical structure of well-being”, Journal of Personality, Vol. 77 No. 4, pp. 1025-1050.

Gidron, B. (2014), "Market-oriented social enterprises employing people with disabilities: a participants' perspective", Journal of Social Entrepreneurship, Vol. 5 No. 1, pp. 60-76.

Grant, A.M. (2007), "Relational job design and the motivation to make a prosocial difference", Academy of Management Review, Vol. 32 No. 2, pp. 393-417. 
Hazenberg, R., Seddon, F. and Denny, S. (2014), "Investigating the outcome performance of work integration social enterprises (WISEs): do WISEs offer 'added value' to NEETs", Public Management Review, Vol. 16 No. 6, pp. 876-899.

Heintzelman, S.J. (2018), "Eudaimonia in the contemporary science of subjective well-being: psychological well-being, self-determination, and meaning in life", in Diener, E., Oishi, S. and Tay, L. (Eds), Handbook of Well-Being, DEF Publishers, Salt Lake City, UT, January, available at: www.nobascholar.com/chapters/18/download.pdf

Ho, A.P. and Chan, K. (2010), "The social impact of work-integration social enterprises in Hong Kong", International Social Work, Vol. 53 No. 1, pp. 33-45, doi: 10.1177/0020872809348950.

Huta, V., Pelletier, L.G., Baxter, D. and Thompson, A. (2012), "How eudaimonic and hedonic motives relate to the well-being of close others", The Journal of Positive Psychology, Vol. 7 No. 5, pp. 399-404.

Jeffery, S. (2005), "Social firms: developing business, economic viability, stakeholder value and worker inclusion”, International Congress Series, Vol. 1282, pp. 1153-1157, doi: 10.1016/j.ics.2005.05.130.

Krupa, T., Sabetti, J. and Lysaght, R. (2019), "How work integration social enterprises impact the stigma of mental illness: negotiating perceptions of legitimacy, value and competence", Social Enterprise Journal, Vol. 15 No. 4, pp. 475-494.

Kyndt, E., Govaerts, N., Keunen, L. and Dochy, F. (2013), "Examining the learning intentions of lowqualified employees: a mixed method study", Journal of Workplace Learning, Vol. 25 No. 3, pp. 178-197.

Lanctôt, N., Corbière, M. and Durand, M.J. (2012), "Job tenure and quality of work life of people with psychiatric disabilities working in social enterprises", Journal of Vocational Rehabilitation, Vol. 37 No. 1, pp. $39-48$.

Law, A. and Staudinger, U.M. (2016), "Eudaimonia and wisdom", in Vittersø, J. (Ed.), Handbook of Eudaimonic Well-Being, Springer International Publishing, Cham, pp. 135-146.

McAdams, D.P. (2008), "Personal narratives and the life story", Handbook of Personality: Theory and Research, The Guilford Press, No. 3, pp. 242-262.

Macaulay, B., Roy, M.J., Donaldson, C., Teasdale, S. and Kay, A. (2018), "Conceptualizing the health and well-being impacts of social enterprise: a UK-based study", Health Promotion International, Vol. 33 No. 5, pp. 748-759.

May, D.R., Gilson, R.L. and Harter, L.M. (2004), "The psychological conditions of meaningfulness, safety and availability and the engagement of the human spirit at work", Journal of Occupational and Organizational Psychology, Vol. 77 No. 1, pp. 11-37.

Munoz, S.A., Farmer, J., Winterton, R. and Barraket, J. (2015), “The social enterprise as a space of wellbeing: an exploratory case study", Social Enterprise Journal, Vol. 11 No. 3, pp. 281-302.

Patton, M.Q. (2001), "Purposive sampling”, in Bryman, A. (Ed.), Ethnography: Sage Benchmarks in Research Methods, SAGE Publications, London, Vol. II, pp. 106-121.

Pratt, M.G. and Ashforth, B.E. (2003), "Fostering meaningfulness in working and meaningfulness at work: an identity perspective", in Cameron, K., Dutton, J.E. and Quinn, R.E. (Eds), Positive Organizational Scholarship, Berrett-Koehler, San Francisco, pp. 309-327.

Pratt, M.G., Pradies, C. and Lepisto, D.A. (2013), “Doing well, doing good, and doing with: organizational practices for effectively cultivating meaningful work", in Dik, B., Byrne, Z. and Steger, M. (Eds), Purpose and Meaning in the Workplace, APA Books, Washington, DC, pp. 173-196.

Rosso, B.D., Dekas, K.H. and Wrzesniewski, A. (2010), "On the meaning of work: a theoretical integration and review”, Research in Organizational Behavior, Vol. 30, pp. 91-127.

Roy, M.J., Donaldson, C. and Baker, R. (2013), "Social enterprise: new pathways to health and wellbeing?”, Journal of Public Health Policy, Vol. 34 No. 1, pp. 55-68.

Ryan, R.M. and Deci, E.L. (2001), "On happiness and human potential: a review of research on hedonic and eudaimonic well being", Annual Review of Psychology, Vol. 52 No. 1, pp. 141-166. 
Ryan, R.M. and Martela, F. (2016), "Eudaimonia as a way of living: connecting Aristotle with selfdetermination theory", in Vittersø, J. (Ed.), Handbook of Eudaimonic Well-Being. International Handbooks of Quality-of-Life, Springer International Publishing, Cham, pp. 109-122.

Ryff, C.D. (1989), "Happiness is everything, or is it? Explorations on the meaning of psychological wellbeing", Journal of Personality and Social Psychology, Vol. 57 No. 6, pp. 1069-1081, doi: 10.1037/ 0022-3514.57.6.1069.

Steger, M.F., Dik, B.J. and Duffy, R.D. (2012), "Measuring meaningful work: the work and meaning inventory (WAMI)", Journal of Career Assessment, Vol. 20 No. 3, pp. 322-337.

Tajfel, H. (1979), "Individuals and groups in social psychology", British Journal of Social and Clinical Psychology, Vol. 18 No. 2, pp. 183-190.

Teasdale, S. (2010), "How can social enterprises address disadvantage? Evidence from an inner-city community", Journal of Nonprofit and Public Sector Marketing, Vol. 22 No. 2, pp. 89-107.

Tiberius, V. (2014), "How theories of well-being can help us”, Journal of Practical Ethics, Vol. 2 No. 2, pp. 1-19.

Villotti, P., Corbière, M., Zaniboni, S. and Fraccaroli, F. (2012), "Individual and environmental factors related to job satisfaction in people with severe mental illness employed in social enterprises", Work, Vol. 43 No. 1, pp. 33-41, doi: 10.3233/wor-2012-1445.

Ward, S.J. and King, L.A. (2016), "Socrates' dissatisfaction, a happiness arms race, and the trouble with eudaimonic well -being", in Vittersø, J. (Ed.), Handbook of Eudaimonic Well-Being, Springer International Publishing, Cham, pp. 523-529, doi: 10.1007/978-3-319-42445-3_35.

Williams, A., Fossey, E. and Harvey, C. (2012), "Social firms: sustainable employment for people with mental illness", Work, Vol. 43 No. 1, pp. 53-62.

Yeoman, R. (2014), "Conceptualising meaningful work as a fundamental human need”, Journal of Business Ethics, Vol. 125 No. 2, pp. 235-251, doi: 10.1007/s10551-013-1894-9.

\section{Further reading}

Chan, A., Ryan, S. and Quarter, J. (2017), "Supported social enterprise: a modified social welfare organization", Nonprofit and Voluntary Sector Quarterly, Vol. 46 No. 2, pp. 261-279.

Guest, G., MacQueen, K. and Namey, E. (2012), Applied Thematic Analysis, Sage Publications, Los Angeles.

Irwin, T. (1985), Aristotle: Nicomachean Ethics, Hackett, Indianapolis.

\section{Corresponding author}

Tamara Bilbija can be contacted at: tamara.bilbija@uji.es

For instructions on how to order reprints of this article, please visit our website: 